\title{
Role of Therapeutic Plasma Exchange in Treatment of Tumefactive Multiple Sclerosis- Associated Low CD4 and CD8 Levels
}

\author{
Kristen Lew ${ }^{\mathrm{a}} \quad$ Nishith Mewada $^{\mathrm{a}} \quad$ Sahana Ramanujam ${ }^{\mathrm{a}}$ \\ Bahareh Hassanzadeh $^{\mathrm{a}}$ John E. Donahue ${ }^{\mathrm{b}}$ \\ Leema Reddy Peddareddygaric ${ }^{\mathrm{C}}$ Robert Moser ${ }^{\mathrm{d}}$ Charles Kososky $^{\mathrm{a}}$ \\ Raji P. Grewal ${ }^{\mathrm{a}}$
}

${ }^{a}$ Neuroscience Institute, Saint Francis Medical Center, Trenton, N.J., USA; ${ }^{b}$ Division of Neuropathology, Department of Pathology, Rhode Island Hospital and the Warren Alpert Medical School of Brown University, Providence, R.I., USA; ${ }^{\circ}$ The Neuro-Genetics Institute, Sharon Hill, Pa., USA; ${ }^{d}$ Department of Pathology, Saint Francis Medical Center,

Trenton, N.J., USA

\section{Keywords}

Central nervous system $\cdot$ Inflammatory demyelinating disease $\cdot$ Lymphopenia $\cdot$ Plasma exchange

\section{Abstract}

We report a 35-year-old healthy male who developed central nervous system inflammatory demyelinating disease consistent with tumefactive multiple sclerosis. About 2 weeks after onset of symptoms and prior to initiation of therapy, the patient had lymphopenia and low CD4 and CD8 levels. His lymphocyte count was 400 cells $/ \mu l(850-3,900$ cells $/ \mu \mathrm{l})$, CD4 was 193 cells $/ \mu \mathrm{l}(490-1,740$ cells $/ \mu \mathrm{l})$ and CD8 was 103 cells $/ \mu \mathrm{l}(180-1,170$ cells $/ \mu \mathrm{l})$. He was treated with intravenous methylprednisolone followed by therapeutic plasma exchange, the levels of CD4 and CD8 normalized, and ultimately, he recovered completely. 


\section{Introduction}

Central nervous system (CNS) inflammatory demyelinating disease (IDD) is characterized by inflammatory lesions associated with loss of myelin and eventually leading to axonal damage. IDD includes a variety of clinical syndromes, the most common include multiple sclerosis (MS), neuromyelitis optica and acute disseminated encephalomyelitis [1-3]. Tumefactive lesions are a rare manifestation of demyelinating disease affecting the CNS. We report the clinical evaluation and treatment of a previously healthy patient with tumefactive IDD.

\section{Case Presentation}

A 35-year-old Caucasian male presented with complaints of memory loss, confusion, headaches and inability to work for the past 2 weeks. Prior to this, the patient was completely normal with no significant medical or neurological history and was gainfully employed as a computer programmer.

General physical examination was normal, the patient was well nourished and in no acute distress. His neurological examination demonstrated a fluctuating mental status and he had an expressive aphasia and was not able to consistently follow a simple or complex command. He could not perform the serial 7 test and was not able to recall any words after 5 min even with prompting. His mental status examination worsened over the course of the hospitalization. The cranial nerve, sensory and motor examinations were normal. The deep tendon reflexes were normoactive with flexor plantar responses.

Routine serum chemistries showed the following tests were normal or negative: complete metabolic panel, urinalysis, prothrombin, and partial thromboplastin time, tuberculosis test, Lyme serology, serology against cysticercosis, varicella, cytomegalovirus, Epstein-Barr virus, cryptococcal antigen, hepatitis B and hepatitis C, human immunodeficiency virus test, rapid plasma reagin, SSA and SSB antibodies, blood cultures, angiotensin-converting enzyme level and erythrocyte sedimentation rate.

A cell blood cell count with differential showed lymphopenia with an absolute lymphocyte count of 400 cells/ $\mu \mathrm{l}$ (reference range: 850-3,900 cells/ $\mu \mathrm{l}$ ). Abnormally low CD4 and CD8 were noted, with 48\% CD4 (30-61\%) with a CD4 count of 193 cells/ $\mu$ l (490-1,740 cells/ $\mu \mathrm{l}), 26 \%$ CD8 $(12-42 \%)$ with a CD8 count of 103 cells/ $\mu \mathrm{l}(180-1,170$ cells/ $\mu \mathrm{l})$, and CD4/CD8 ratio of 1.88 (0.86-5.00).

A lumbar puncture was performed and cerebrospinal fluid (CSF) analysis showed a white blood cell count of $200 / \mu \mathrm{l}(0-5 / \mu \mathrm{l})$ with a differential count of $96 \%$ lymphocytes, $4 \%$ monocytes and with 0 neutrophils. The CSF myelin basic protein was $5.1 \mu \mathrm{g} / \mathrm{l}(0.0-0.4 \mu \mathrm{g} / \mathrm{l})$ with five oligoclonal bands (reference range: 0 bands). Both CSF and serum toxoplasma antibody and herpes simplex tested by polymerase chain reaction were negative. A Gram stain, Indian ink stain, and CSF culture were negative. CSF cytology showed no malignant cells and no viral inclusions.

A computerized tomography (CT) scan of the chest, abdomen and pelvis revealed no abnormalities. A CT scan of the head on admission showed several ill-defined, nonspecific hypodense lesions in the cerebral hemisphere bilaterally. A magnetic resonance imaging (MRI) of the brain performed with and without contrast showed multiple supratentorial ringenhancing lesions bilaterally, distributed throughout the cerebral hemispheres, with both deep and superficial cortical lesions, measuring up to $16 \mathrm{~mm}$ in diameter. These were associated with surrounding vasogenic edema (fig. 1). The lesions did not show evidence of re- 
stricted diffusion. The cerebellum was spared and there was no midline shift or extra-axial collection. The patient underwent left frontal craniotomy and open biopsy of the brain lesion, and a diagnosis of an inflammatory demyelinating process was made (fig. 2).

The patient was started on methylprednisolone 1,000 mg intravenously daily for 5 days and subsequently transferred to a rehabilitation program for intensive physical and occupational therapy. Initially the patient showed some neurological improvement but he relapsed and was readmitted to hospital 2 weeks after completing the course of steroids with complaints of headache and confusion. His neurologic examination at this time showed predominantly abnormalities related to his mental status and with personality changes. A repeat MRI of the brain with and without contrast showed multiple foci of mixed signal abnormalities within the cerebral hemispheres. There were some new lesions noted, and some of the lesions seen on the prior images were smaller and showed less enhancement.

The patient's condition improved with intravenous steroids, and he was discharged home 10 days later with tapering steroids orally. He was readmitted 10 days later with a generalized tonic-clonic seizure and increased confusion and was started on lacosamide (50 $\mathrm{mg}$ a day orally) and also intravenous methylprednisolone $500 \mathrm{mg}$ daily for 5 days. He also received therapeutic plasma exchange of six treatments over 2 weeks and he started to improve. He was discharged home with lacosamide $100 \mathrm{mg}$ twice a day orally and oral prednisolone starting at $20 \mathrm{mg}$ a day tapering with reduced doses, which was finished in a week. The patient was maintained on monthly plasma exchange for ongoing treatment.

A repeat spinal tap 3 months later showed the following CSF results: glucose $98 \mathrm{mg} / \mathrm{dl}$ (40-70 mg/dl), protein $31 \mathrm{mg} / \mathrm{dl}(15-45 \mathrm{mg} / \mathrm{dl})$, white blood cell count $2 / \mu \mathrm{l}(2-5 / \mu \mathrm{l})$ and three oligoclonal bands were noted (reference range: 0 ). Additional tests performed at this time for CSF basic myelin protein and IgG synthesis were negative or normal.

Repeat tests of the CD4 and CD8 parameters were performed 7 months after onset of symptoms and were as follows: lymphocytes 1,555 cells/ $\mu \mathrm{l}(850-3,900$ cells/ $\mu \mathrm{l}), \mathrm{CD} 4660$ cells/ $\mu \mathrm{l}(490-1,740$ cells/ $\mu \mathrm{l})$, and CD8 289 cells/ $\mu \mathrm{l}(180-1,170$ cells/ $\mu \mathrm{l})$. These were repeated at yearly intervals for 2 years and remained within normal limits.

Serial cranial MRI scans done with and without gadolinium monthly for 3 months following initial evaluation and then yearly showed evolution of the existing lesions without the development of new lesions.

Over the next 2 years, the patient was maintained on the regimen of monthly therapeutic plasma exchange and had no further recurrence of symptoms. He slowly improved to the point that he was able to return to work. Ultimately, his neurological examination returned to normal and, at present, 6 months later with no treatment, he has been stable.

This research follows local Institutional Review Board-approved policies and procedures. The patient provided written informed consent to participate in this study.

\section{Discussion}

Our patient's presentation and radiological and pathological findings suggest tumefactive MS [1]. There are few reports specifically addressing the management of patients with tumefactive MS [4]. One reports a patient with a diagnosis of relapsing-remitting MS presenting with aggressive disease with multiple tumefactive lesions and not responding to standard treatment with corticosteroids who was successfully treated in hospital with a total of five plasma exchanges that were performed every other day. However, in this case, the disease progressed during the next year [5]. Another article discusses a patient who failed to 


\section{Case Reports in Neurology}

Lew et al.: Role of Therapeutic Plasma Exchange in Treatment of Tumefactive Multiple Sclerosis-Associated Low CD4 and CD8 Levels

completely resolve with initial therapy with steroids and was then treated with azathioprine, mycophenolate mofetil, rituximab and cyclophosphamide [4]. Interestingly, in contrast to our patient, he was not treated with plasma exchange. In our patient, plasma exchange was initially performed a total of 6 times over 2 weeks with 1.0-1.5 plasma volume exchange $(4,000 \mathrm{ml})$ per procedure with replacement fluid of $5 \%$ human albumin. This was repeated on an outpatient basis monthly for 2 years. This regimen was highly effective as his neurological examination returned to normal. Furthermore, he had no further recurrence or relapse of his symptoms. There have been previous reports of the utility of plasma exchange in patients with CNS IDD but not specifically tumefactive MS [6].

A unique aspect of our investigation of this patient are the immunological parameters tested in the patient upon initial presentation and not on any treatment. His CD4 and CD8 counts were low, and to our knowledge, this is the first time this laboratory abnormality has been observed in a patient with IDD. There have been studies of the role of CD4 and CD8 cells in MS, where the implications of low levels of both of these cell types is not clear [7-9], although a low CD4 count has been described in a number of conditions such as HIV disease and levels of CD8 cells are reduced in patients treated with dimethyl fumarate [10]. However, the combination of reduced values of both the CD4 and CD8 levels has not been reported in any disorder $[9,11]$. In this patient, this abnormality could be due to a prior viral infection which may have initiated the process of CNS demyelination. Alternatively, it may represent the response of the immune system to the beginning of the disease process.

Whether abnormally low CD4 and CD8 levels are involved in the pathophysiology of IDD will require further confirmation with studies investigating CD4 and CD8 parameters in patients early in the clinical course prior to initiation of any therapy. If our results are confirmed, levels of CD4 and CD8 could represent a biomarker for tumefactive CNS IDD. Regardless of the specific pathophysiology, therapeutic plasma exchange should be a consideration in atypical cases of IDD consistent with tumefactive MS.

\section{Statement of Ethics}

Informed consent was obtained from the patient, and the study was conducted following local Institutional Review Board-approved policies and procedures.

\section{Disclosure Statement}

The authors declare that there is no conflict of interest regarding the publication of this paper.

\section{References}

1 Lucchinetti CF, Gavrilova RH, Metz I, Parisi JE, Scheithauer BW, Weigand S, Thomsen K, Mandrekar J, Altintas A, Erickson BJ, König F, Giannini C, Lassmann H, Linbo L, Pittock SJ, Brück W: Clinical and radiographic spectrum of pathologically confirmed tumefactive multiple sclerosis. Brain 2008;131(Pt 7):1759-1775.

2 Hu W, Lucchinetti CF: The pathological spectrum of CNS inflammatory demyelinating diseases. Semin Immunopathol 2009;31:439-453.

-3 Karussis D: The diagnosis of multiple sclerosis and the various related demyelinating syndromes: a critical review. J Autoimmun 2014;48-49:134-142. 


\section{Case Reports in Neurology}

\begin{tabular}{l|l}
\hline Case Rep Neurol 2016;8:179-184 \\
\hline DOI: 10.1159/000448704 & $\begin{array}{l}\text { @ 2016 The Author(s). Published by S. Karger AG, Basel } \\
\text { www.karger.com/crn }\end{array}$ \\
\hline
\end{tabular}

Lew et al.: Role of Therapeutic Plasma Exchange in Treatment of Tumefactive Multiple Sclerosis-Associated Low CD4 and CD8 Levels

4 Siffrin V, Müller-Forell W, von Pein H, Zipp F: How to treat tumefactive demyelinating disease? Mult Scler 2014;20:631-633.

5 Ikeda KM, Lee DH, Fraser JA, Mirsattari S, Morrow SA: Plasma exchange in a patient with tumefactive, corticosteroid-resistant multiple sclerosis. Int J MS Care 2015;17:231-235.

6 Magaña SM, Keegan BM, Weinshenker BG, Erickson BJ, Pittock SJ, Lennon VA, Rodriguez M, Thomsen K, Weigand S, Mandrekar J, Linbo L, Lucchinetti CF: Beneficial plasma exchange response in central nervous system inflammatory demyelination. Arch Neurol 2011;68:870-878.

7 Hohlfeld R, Dornmair K, Meinl E, Wekerle H: The search for the target antigens of multiple sclerosis, part 1: autoreactive CD4+ T lymphocytes as pathogenic effectors and therapeutic targets. Lancet Neurol 2016;15:198-209.

8 Hohlfeld R, Dornmair K, Meinl E, Wekerle H: The search for the target antigens of multiple sclerosis, part 2: CD8+ T cells, B cells, and antibodies in the focus of reverse-translational research. Lancet Neurol 2016;15:317-331.

-9 Pirko I, Chen Y, Lohrey AK, McDole J, Gamez JD, Allen KS, Pavelko KD, Lindquist DM, Dunn RS, Macura SI, Johnson AJ: Contrasting roles for CD4 versus CD8 T-cells in a murine model of virally induced 'T1 black hole' formation. PLoS One 2012;7:e31459.

-10 Spencer CM, Crabtree-Hartman EC, Lehmann-Horn K, Cree BA, Zamvil SS: Reduction of CD8(+) T lymphocytes in multiple sclerosis patients treated with dimethyl fumarate. Neurol Neuroimmunol Neuroinflamm 2015;2:e76.

-11 Lu W, Mehraj V, Vyboh K, Cao W, Li T, Routy JP: CD4:CD8 ratio as a frontier marker for clinical outcome, immune dysfunction and viral reservoir size in virologically suppressed HIV-positive patients. J Int AIDS Soc 2015;18:20052.
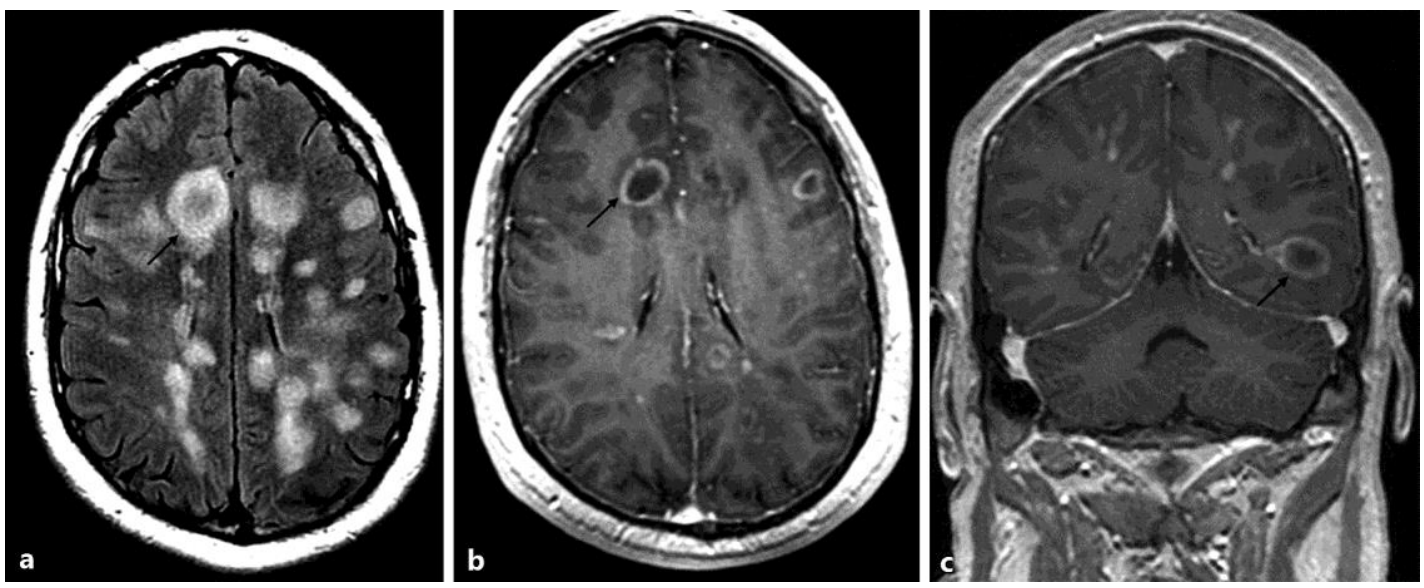

Fig. 1. Cranial MRI of the brain with and without contrast. a T2 flair image demonstrates several globoid/ ovid T2-enhancing areas with edema. b T1 ring-enhancing areas with paucity of mass effect or edema. c Coronal view of T1 ring-enhancing areas post contrast without mass effect or edema. 


\section{Case Reports in Neurology}
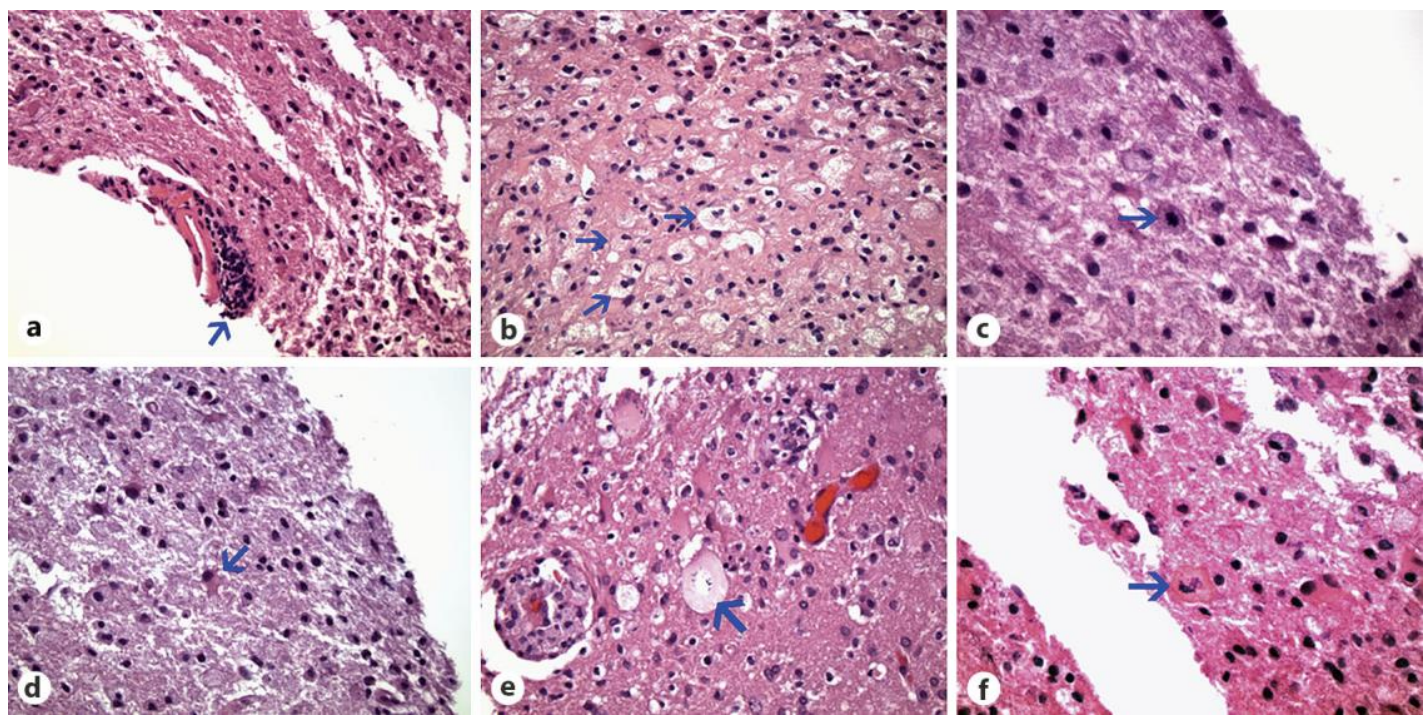

Fig. 2. Sections showing hematoxylin and eosin stain of the brain tissue biopsy of the patient. a, b, d, e Sections showing brain tissue at $400 \times$ magnification. a Lymphocytes: focal perivascular lymphocytic cuffing (arrow). b Macrophages: widespread infiltration of macrophages (arrows) within the brain tissue. $\mathbf{d}$ Gemistocytes: scattered reactive, gemistocytic astrocytes (arrow). e Possible Creutzfeldt cell: a very large cell with a granular mitosis (arrow), suggestive of a Creutzfeldt astrocyte, is seen in this biopsy. c, f Sections showing brain tissue at $600 \times$ magnification. c Macrophage with mitosis: a mitosis (arrow) is seen within one of the infiltrating macrophages. $\mathbf{f}$ Compelling Creutzfeldt cell: a cell with eosinophilic cytoplasm and granular mitosis (arrow), consistent with a Creutzfeldt astrocyte, is seen in this biopsy. Creutzfeldt astrocytes are nonspecific in general but are classically seen in demyelinating diseases. 